\title{
Prueba piloto para la implementación de la guía de mediación policial para el sector rural en dos centros de poblado
}

\section{Pilot test for the implementation of the police mediation guide for the rural sector in two population centers}

\section{Teste pilloto para a implementacao do guila de mediacao policial para o setor rural em dois centros de popullacao}

\section{Johanderson Aparicio Reyes ${ }^{2}$ Luis Daniel Arboleda Maya ${ }^{3}$ \\ Leidy Carolina Álzate Payeras ${ }^{4}$ Nubia Edith Céspedes Prieto ${ }^{5}$}

\section{Colombia}

1 Artículo producto de la investigación realizada al interior del Grupo de Investigación ECSAN, en torno a la mediación policial en el ámbito rural.

2 Especialista en servicio de policía, Ingeniero mecánico Escuela de Cadetes de Policía "General Francisco de Paula Santander" jj.aparicio@correo.policia.gov.co, Orcid: https://orcid.org/0000-0002-6076-9474

Teléfono: +57 3057540153 Bogotá D.C. - Colombia

3 Especialista en servicio de policía, Abogado, Especialista en derecho administrativo

Escuela de Cadetes de Policía "General Francisco de Paula Santander" luis.arboleda3884@correo.policia.gov.co, Orcid: https://orcid. org/0000-0002-6472-824X Teléfono: +573128171222 Bogotá D.C. - Colombia

4 Especialista en servicio de policía, Comunicadora social y periodista Escuela de Cadetes de Policía "General Francisco de Paula Santander" leidy.alzate@correo.policia.gov.co, Orcid: https://orcid.org/0000-0003-4365-7806 Teléfono: +573003464505 Bogotá D.C. - Colombia

5 Doctora en Ciencias, Magister en ciencias químicas, Licenciada en química y biología, Ingeniera ambiental, Docente de la ECSAN, Integrante del grupo de investigación ECSAN categorizado por Colciencias en C, Investigadora asociada (Colciencias) necespedesp@unal.edu.co, Orcid: https://orcid.org/0000-0001-6334-989X.Teléfono: +57 3158696874 Bogotá D.C.-Colombia 


\section{RESUMEN}

El presente estudio mixto secuencial de validación de la Guía para fortalecer la implementación de la mediación policial en el sector rural de Colombia, es importante para la Policía Nacional de Colombia por cuanto impacta el proceso de innovación y mejora continua del servicio de policía en el ámbito rural mediante la valoración y ajustes de un documento estructurado en el marco de una investigación aplicada en la Escuela de Policía Gabriel González.

El alcance exploratorio del estudio se ejecuta en tres fases que permiten aplicar la totalidad de los módulos incluidos en la guía valiéndose de un enfoque cuantitativo no experimental $y$ transversal para la valoración los conflictos en las zonas seleccionadas y un enfoque cualitativo que retroalimenta las condiciones generales del proceso de validación.

Los resultados del estudio permiten establecer las mejoras aplicables a la Guía para fortalecer la implementación de la mediación policial en el sector rural de Colombia para que se adecue a las características necesarias para su implementación en el ámbito rural, específicamente en el corregimiento Palomino (Valle del Cauca) y la vereda de Torres (Cauca).

PALABRAS CLAVE: Colombia, implementación, mediación, rural, policial, validación.

\footnotetext{
ABSTRACT

This mixed sequential study of validation of the Guide to strengthen the implementation of police mediation in the rural sector of Colombia, is important for the National Police of Colombia because it impacts the process of innovation and continuous improvement of the police service in the field rural area by evaluating and adjusting a structured document within the framework of an applied investigation at the Gabriel González Police School.
}

The exploratory scope of the study is carried out in three phases that allow the application of all the modules included in the guide using a nonexperimental and cross-sectional quantitative approach to assess conflicts in the selected areas and a qualitative approach that provides feedback on the general conditions of the validation process.

The results of the study allow to establish the improvements applicable to the Guide to strengthen the implementation of police mediation in the rural sector of Colombia so that it adapts to the characteristics necessary for its implementation in the rural area, specifically in the Palomino district (Valle del Cauca) and the village of Torres (Cauca).

KEYWORKS: Colombia, implementation, mediation, rural, police, validation.

\section{SUMARIO}

O presente estudo sequencial misto de validação do Guia para fortalecer a implementação da mediação policial no setor rural da Colômbia é importante para a Polícia Nacional da Colômbia porque impacta o processo de inovação e melhoria contínua do serviço policial no campo área rural avaliando e ajustando um documento estruturado no marco de uma investigação aplicada na Escola de Polícia Gabriel González.

O escopo exploratório do estudo é realizado em três fases que permitem a aplicação de todos os módulos incluídos no guia usando uma abordagem quantitativa não experimental e transversal para avaliar os conflitos nas áreas selecionadas e uma abordagem qualitativa que fornece feedback sobre as condições gerais do estudo. processo de validação.

Os resultados do estudo permitem estabelecer as melhorias aplicáveis ao Guia para fortalecer a implementação da mediação policial no setor rural da Colômbia para que se adapte às características necessárias para sua 
implementação na área rural, especificamente no distrito de Palomino (Valle del Cauca) e a aldeia de Torres (Cauca).

PALAVRAS-CHAVE: Colômbia, implementação, mediação, rural, polícia, validação.

\section{INTRODUCCIÓN}

La ley 1801 de 2016 faculta a los funcionarios de la Policía Nacional de Colombia para el ejercicio de las acciones de mediación policial como medio inmaterial de carácter preventivo aplicable a situaciones de conflicto entre ciudadanos. En ese sentido la institución policial ha estandarizado este medio de policía mediante un documento de consulta titulado: Guía para realizar la mediación policial en Colombia (1PRGU-0004) que hace parte del proceso misional de prevención, en la que se establecen los criterios generales para su correcta ejecución.

En ese sentido la Escuela de Policía "Gabriel González" ejecutó una investigación formativa en la que se alcanzó una Guía para fortalecer la implementación de la mediación policial en el sector rural de Colombia, que requiere ser valorada en cuanto a su aplicabilidad por parte de los uniformados que conforman el Modelo Nacional de Vigilancia Comunitaria por Cuadrantes (MNVCC) en aquellas poblaciones catalogadas como rurales.

De acuerdo a lo anterior, se estableció como objetivo la validación práctica de las acciones de implementación para la mencionada guía, mediante una prueba piloto que permita la retroalimentación del proceso y la proposición de ajustes.

El presente estudio determina como alcance la ejecución de acciones prácticas basadas en los preceptos trazados en la Guía para fortalecer la implementación de la mediación policial en el sector rural de Colombia, en el corregimiento Palomino (Valle del Cauca) y la vereda de Torres (Cauca) que son categorizados como centros de poblado rurales, teniendo presente las eventuales limitaciones causadas por la necesidad de ejecutar desplazamientos desde la Escuela de Cadetes de Policía "General Francisco de Paula Santander" hasta los lugares objeto del estudio que se restringen por el estado de emergencia nacional causado por el COVID-19.

La metodología establecida para el estudio es de tipo mixto secuencial en la que el componente cuantitativo es transversal y no experimental de alcance exploratorio para conocer el comportamiento de los conflictos en cada localidad seleccionada. En el componente cualitativo fenomenológico se valora la aplicabilidad de la mencionada guía desde el punto de vista de los actores que ejecutan la medicación policial.

La primera fase del estudio se centró en la valoración de los conflictos en cada una de las localidades seleccionadas, mientras que en la segunda fase se validan las condiciones generales de aplicabilidad de la Guía para fortalecer la implementación de la mediación policial en el sector rural de Colombia. En la tercera y última fase de integración, se plantean propuestas para mejorar la estructura general y la aplicabilidad de la guía en el contexto rural colombiano.

Los resultados de esta investigación se constituyen en un importante referente para la Policía Nacional de Colombia por cuanto se aplican los resultados de una investigación propositiva para caracterizar su efectividad en el proceso de implementación de la mediación policial en el ámbito rural. Su aplicación se orienta al contexto educativo de la institución desde donde se toman las decisiones en relación con la proposición de nuevas herramientas documentales que dinamicen el servicio de policía en el ámbito rural. 


\section{LA MEDIACIÓN POLICIAL EN EL CONTEXTO RURAL DE COLOMBIA}

La mediación en el ámbito policial, ha tenido una evolución paralela a la transformación institucional y a la creación de un entorno jurídico favorable para la implementación de esta herramienta necesaria para la óptima prestación del servicio de policía, con el fin de plantear una estrategia para la solución de las problemáticas de convivencia. Según, (Steele Garza, 2018) la mediación policial, pretende instaurar una nueva orientación en las actividades cotidianas de la seguridad pública. La mediación policial es viable y factible para la reconstrucción de relaciones interpersonales e intergrupales que fortalece el capital social, previniendo las conductas antisociales. La mediación policial supone un nuevo protocolo de intervención más proactivo que reactivo, que atiende y entienda las diferencias de la comunidad, pero con énfasis a la cultura del dialogo y sana convivencia.

La RAE define mediación como: Acción y efecto de mediar o actividad desarrollada por una persona de confianza quienes sostienen intereses contrapuestos, con el fin de evitar un litigio.

Según (Riley, Prenzler, \& McKillop, 2018), en Australia y Nueva Zelanda, la mediación Policial, fue implementada mediante guías, los datos obtenidos de fuentes policiales y de agencias de supervisión en este estudio mostraron que las opciones se limitaban a la resolución informal realizada por oficiales superiores, con un enfoque aparente en la mejora del comportamiento, pero sin datos significativos disponibles públicamente sobre los resultados.

(Becerril \& Reche, 2016), recuerdan la función de la mediación pese a que no es dentro del ámbito policial, permite otra función de la actividad de mediar el cual dice:
"Así, LA MEDIACIÓN HABRÁ CUMPLIDO SU FUNCIÓN AL PROCURAR EL CONOCIMIENTO DE LAS PERSONAS $Y$ FOMENTAR SU COMUNICACIÓN, LO CUAL LES PERMITIRÁ ENTENDERSE $Y$ CONVIVIR DE UN MODO MENOS CONFLICTIVO EN EL FUTURO. LA MEDIACIÓN SE CONFIGURA COMO UNA FORMA «PARA» (Y NO «DE») RESOLUCIÓN ALTERNATIVA DEL CONFLICTO, A TRAVÉS DE LA CUAL LAS PARTES EN CONFLICTO LLEGAN POR SÍ MISMAS A UNA SOLUCIÓN CON LA AYUDA DE UN PROFESIONAL, EL MEDIADOR, QUIEN, CON SU FORMACIÓN, OFRECE A LAS PARTES NUEVAS VÍAS DE DIÁLOGO Y ENTENDIMIENTO" (Becerril \& Reche, 2016, pág. 4)

La necesidad de fortalecer las relaciones sociales, culturales, ambientales y de seguridad en las zonas rurales de Colombia han Ilevado a la Policía a conocer, aprender y practicar los mecanismos alternativos de resolución de conflictos, con énfasis en el arbitraje, la conciliación y últimamente la mediación como un medio de policía que facilita la atención de casos de conflicto entre los ciudadanos que han logrado con este medio de policía alcanzar acuerdos favorables para las partes desescalonando el conflicto y en otros casos previniendo futuros o mayores desacuerdos que llevarían a un deterioro de las relaciones y la afectación directa de la convivencia pacífica.

"LA MEDIACIÓN TIENE UN PROFUNDO SENTIDO ÉTICO Y MORAL. EN EL CASO DE LA MEDIACIÓN POLICIAL, ESE SENTIDO SE HACE AÚN MÁS PROFUNDO, PORQUE SU PUESTA EN MARCHA EN LA VIDA COTIDIANA DE LA CONVIVENCIA Y LA SEGURIDAD EXIGE FOMENTAR EL DESARROLLO DE ACTITUDES $Y$ HABILIDADES NECESARIAS PARA INTERACCIONES DE PROXIMIDAD ENTRE EL PERSONAL UNIFORMADO Y LA COMUNIDAD, POR MEDIO DE UNA RELACIÓN DIRECTA CON LA ESFERA DE LOS VALORES Y 
LAS CREENCIAS DE LOS COPARTICIPANTES EN EL ENCUENTRO MEDIADOR" (Cámara de Comercio de Bogotá, 2017, pág. 12)

Es decir que no solo es una actividad independiente, sino que el mediador debe ser ético, integral y honesto dentro de su proceso como mediador, pera el correcto desarrollo de su actividad como intermediario en un conflicto.

Para fortalecer las relaciones sociales, culturales, ambientales y de seguridad en las zonas rurales de Colombia, se debe aplicar una prueba piloto que establezca si la guía que se tiene es eficaz para la zona y que modificaciones se le pueden realizar, Según (Hernández, Fernandez, \& Baptista, 2014) una prueba piloto, consiste en administrar el instrumento a una pequeña muestra de casos para probar su pertinencia y eficacia (incluyendo instrucciones), así como las condiciones de la aplicación y los procedimientos involucrados. A partir de esta prueba se calculan la confiabilidad y la validez iniciales del instrumento. Para la aplicación de la guía es importante establecer las propiedades y características del conflicto en la región con el fin de presentar alternativas de prevención y enfocar mecanismos orientados a la solución dialógica del conflicto, para esto puede recurrir a dos opciones.

Es tan clara la función y el papel que se tiene en esta actividad que la institución ha creado escuelas de formación en el carácter de mediación policial, para garantizar su efectividad en la función de esta, al ser de carácter preventivo, el hecho de mediar, evita futuros actos contrarios a la convivencia.

La medición no es algo inesperado, esta debe tener unas características como: un objetivo, noción del conflicto, un rol de mediador y los resultados que se esperan en la ejecución de esta "El asumir los retos en convivencia y seguridad con el fin primordial de mantener de las condiciones necesarias para el ejercicio de los derechos y libertades públicas" (Cámara de Comercio de Bogotá, 2017, pág. 31), es decir el personal de la institución debe tener presente este tipo de actividades y lo planteado por el artículo 218 de la Constitución Colombiana, como Colombia es un país en constante cambio la institución dentro su accionar debe transformase para el mejoramiento de la misma y la nación.

Este esfuerzo institucional por mantener la doctrina relacionada con la mediación policial, se ha materializado mediante productos de investigación ejecutados periódicamente como es el caso del libro titulado: "La mediación como herramienta de paz en el servicio de policía" ejecutada por el grupo de investigación de la Escuela de Cadetes de policía "General Francisco de Paula Santander", en donde se abordan el tema de mediación de cara al posconflicto colombiano (Suarez, Camacho, Céspedez, Rozo, \& Matiz, 2016). En ese mismo año se publicó un artículo sobre el rol de mediador de la Policía Nacional de Colombia en el posconflicto donde se expone la revisión teórica de a los estudios recientes en donde se involucra la fuerza pública y las situaciones de posconflicto, logrando establecer los nuevos roles que debe cumplir la institución policial en la etapa del posconflicto colombiano (Céspedes \& Ramirez, 2016).

También se referenció el artículo publicado por (Camacho \& Céspedes, 2018) titulado Habilidades socio-emocionales: un elemento esencial en el policía como mediador en Colombia, donde las autoras analizan el conjunto de habilidades asociadas al perfil del policía en el marco de su función como mediador en el servicio de policía, logrando establecer que el conocimiento de sí mismo, la empatía, la integridad, el autocontrol emocional y las situaciones de estrés, son condiciones que deben potencializarse en los uniformados para 
mejorar su capacidad al momento de ejecutar acciones de mediación de conflictos.

Otro de los estudios relacionados con la incidencia de las habilidades psicosociales en el marco de servicio de policía fue publicado en la revista Boletín Redipe en el mes de mayo de 2020 , donde los autores exponen los resultados de su investigación sobre el fortalecimiento de las habilidades psicosociales de los policías para mejorar la prestación del servicio de policía que reciben los colombianos, destacándose como producto de investigación una propuesta de acción formativa a nivel de diplomado para los funcionarios de la Policía Nacional de Colombia (Céspedes, y otros, 2020).

"A continuación, se hace un recuento de los enfoques policiales en Colombia desde 1993 hasta 2014 año en que se estableció el Modelo Nacional de Vigilancia Comunitaria por Cuadrantes (MNVCC), el cual se mantiene vigente hasta la fecha... Así mismo, se hace un recuento de cómo se concibió el proyecto piloto de mediación policial y las etapas que definieron las características del modelo de mediación policial actual en Colombia, que llevaron a una conceptualización tanto en aspectos dogmáticos como procedimentales, los cuales establecen diferencias significativas respecto a la mediación policial de otros cuerpos de la policía." (Cámara de Comercio de Bogotá, 2017, pág. 31)

La constante medición de esta actividad por medio de pruebas piloto es la muestra clara de que cada conflicto presentado en el país con el paso de los años es diferente y así mismo debe ser su intervención; esta varía de acuerdo a la región del país donde se presente este fenómeno.
Es decir, esto no es una práctica nueva un ejemplo de esta actividad, son las aplicadas en Bogotá y Cundinamarca, para dar asertivamente con el desarrollo de la guía; no es simplemente intervenir por intervenir, tal como se mencionaba anteriormente la guía se debe plantear con objetivos para permitir el correcto análisis del éxito de la estrategia.

Desde el punto de vista normativo, la ley 1801 de 2016 por la cual se establece el Código Nacional de Convivencia y Seguridad, en su artículo número 149 establece los medios de policía en dos clasificaciones, medios materiales a inmateriales, entre los medios inmateriales se encuentra la orden de policía, el permiso excepcional, reglamentos, autorización y la mediación policial, estos medios tienen que ver con manifestaciones de tipo verbal o escrito con el propósito de comunicar las decisiones de las autoridades de policía Ciudadana (Congreso de la República de Colombia , 2016).

Es importante distinguir entre la medicación policial como medio inmaterial de policía reglamentado en la ley 1801 de 2016, y el mecanismo mediación establecido en el artículo 523 del Código de Procedimiento Penal (ley 906 de 2004), este segundo mecanismo se fundamenta en el concepto de permitir el intercambio de opiniones entre la víctima y el imputado para solucionar el conflicto que en este caso es asistido por un tercero neutral, articular o servidor público que designe la fiscalía general de la nación (Congreso de la Republica de Colombia , 2004).

Ahora bien, la Escuela de Policía Gabriel González - "ESGON" en el marco de una investigación formativa, logró la creación de una Guía para fortalecer la implementación de la mediación policial en el sector rural de Colombia, la cual comprende una validación en el departamento del Tolima. 
La mencionada guía incluye en el módulo número 1 , dos alternativas para establecer las propiedades y características del conflicto en una zona geográfica, la primera alternativa se relaciona con la revisión y análisis de los reportes estadísticos de Sistema de Información Estadístico, Delincuencial y Contravencional (SIEDCO) de la Policía Nacional de Colombia, adicionalmente propone la revisión de los informes de percepción de seguridad que elabora la cámara de comercio y las autoridades locales como las alcaldías y/o gobernaciones.

La alternativa número 2, establece la aplicación de una encuesta de percepción de seguridad con instrumentos predefinidos, seguidamente propone la categorización de los conflictos de la comunidad a partir de la tabulación de los datos. Finalmente determina que se proponga estrategias para la prevención de conflictos mediante acciones de educación, campañas y otros medios de policía preventivos de cara a mantener las condiciones acertadas de convivencia y seguridad en el ámbito rural.

En este mismo módulo se describe la dinámica de los conflictos en la comunidad rural, haciendo claridad en que su variación está ligada a las condiciones culturales, emocionales y de las experiencias de conflictos dentro de la misma comunidad.

En el módulo número 2 de la Guía para fortalecer la implementación de la mediación policial en el sector rural de Colombia, se realiza una contextualización de la mediación policial en el marco del Código Nacional de Policía y Convivencia, aclarando entre otros aspectos su definición, antecedentes en Colombia y el marco legal.

También se divulgan las habilidades que requieren los medidores policiales para su debido ejercicio ante la sociedad colombiana, mencionado cinco aspectos: comunicación estratégica, regulación emocional, capacidad de negociación, creatividad y redacción de documentos. Adicionalmente establece la necesidad de que el mediador ejecute una valoración del conflicto al momento de intervenir, teniendo como derroteros las condiciones de dialogo, relaciones entre las partes, niveles de tensión y la incomodidad que eventualmente exista entre los involucrados en el conflicto.

En la parte final de este módulo se hace referencia a los dos tipos de procedimiento establecidos por la Policía Nacional de Colombia para ejecutar la mediación policial, el primero de ellos corresponde al procedimiento in situ que se aplica por los uniformados en el mismo lugar donde se tiene conocimiento del conflicto, el segundo se denomina: procedimiento en estación policial, que refiere diez (10) acciones para su efectiva ejecución.

En el módulo número 3 de la guía, menciona las líneas generales para la implementación de la medicación policial en el sector rural, enfatizando en el proceso, el modelo de seguimiento y la relación de instituciones que ofertan la capacitación relacionada con la mediación policial.

El módulo numero 4 presenta una lectura relacionada con las justificaciones para la divulgación de la mediación policial en las comunidades rurales y los fines que persigue la Guía para fortalecer la implementación de la mediación policial en el sector rural de Colombia, relacionando algunas estrategias para la promoción de la mediación y los instrumentos de seguimiento y evaluación a los procesos que se identifican en el sector rural.

Por otra parte, y para la mejor comprensión del objeto de estudio de la presente investigación, es necesario conocer algunas de las condiciones sociodemográficas de los lugares donde se aplicaron los instrumentos de percepción de la seguridad. 
Vereda de Torres (Popayán - Cauca). En el sector rural de Popayán en el departamento de Cauca, se cuentan unos 300.837 habitantes de los cuales el $86 \%$ de la población se ubica en el área urbana, el $14 \%$ está asentado en el ámbito rural y específicamente en la vereda de Torres se habitan al menos 2046 habitantes.

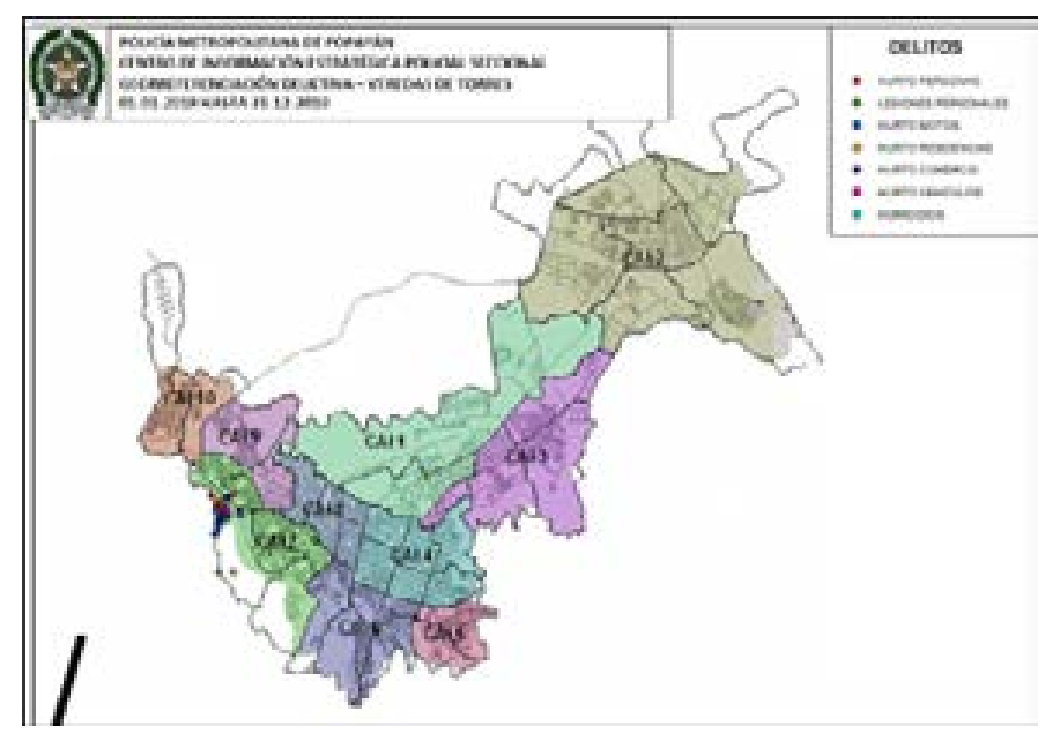

Figura 1, Georeferenciación delictiva en vereda de Torres (Policía Nacional de Colombia, 2020)

A continuación, se presentan los datos del registro nacional de Medidas Correctivas (RNMC) de la Policía Nacional correspondientes a la vereda de Torres (Popayán).

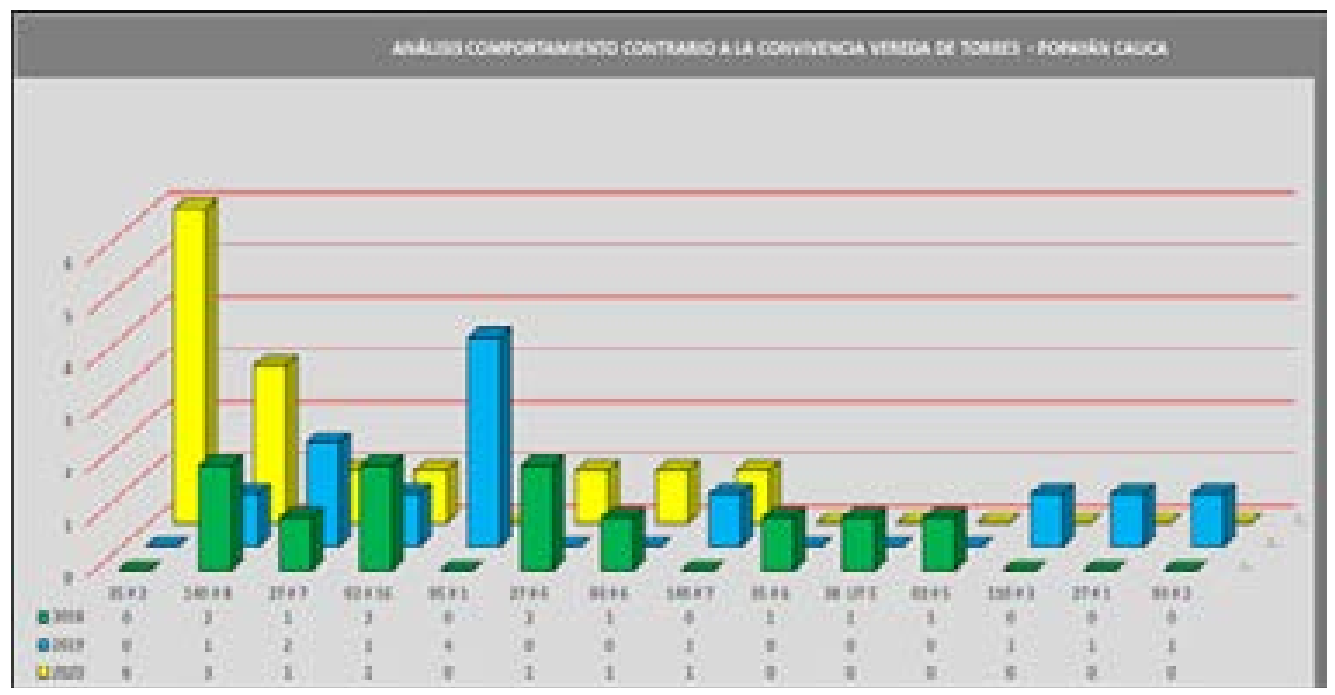

Figura 2, análisis comportamientos contrarios a la convivencia, vereda torres - Popayán (Cauca) (Policía Nacional de Colombia, 2020) 
Corregimiento Palomino (Sevilla - Valle del Cauca). Este corregimiento cuenta con una población urbana y rural de 425 habitantes aproximadamente, destacándose como principal labor económica la agricultura donde se distinguen agricultores y jornaleros.

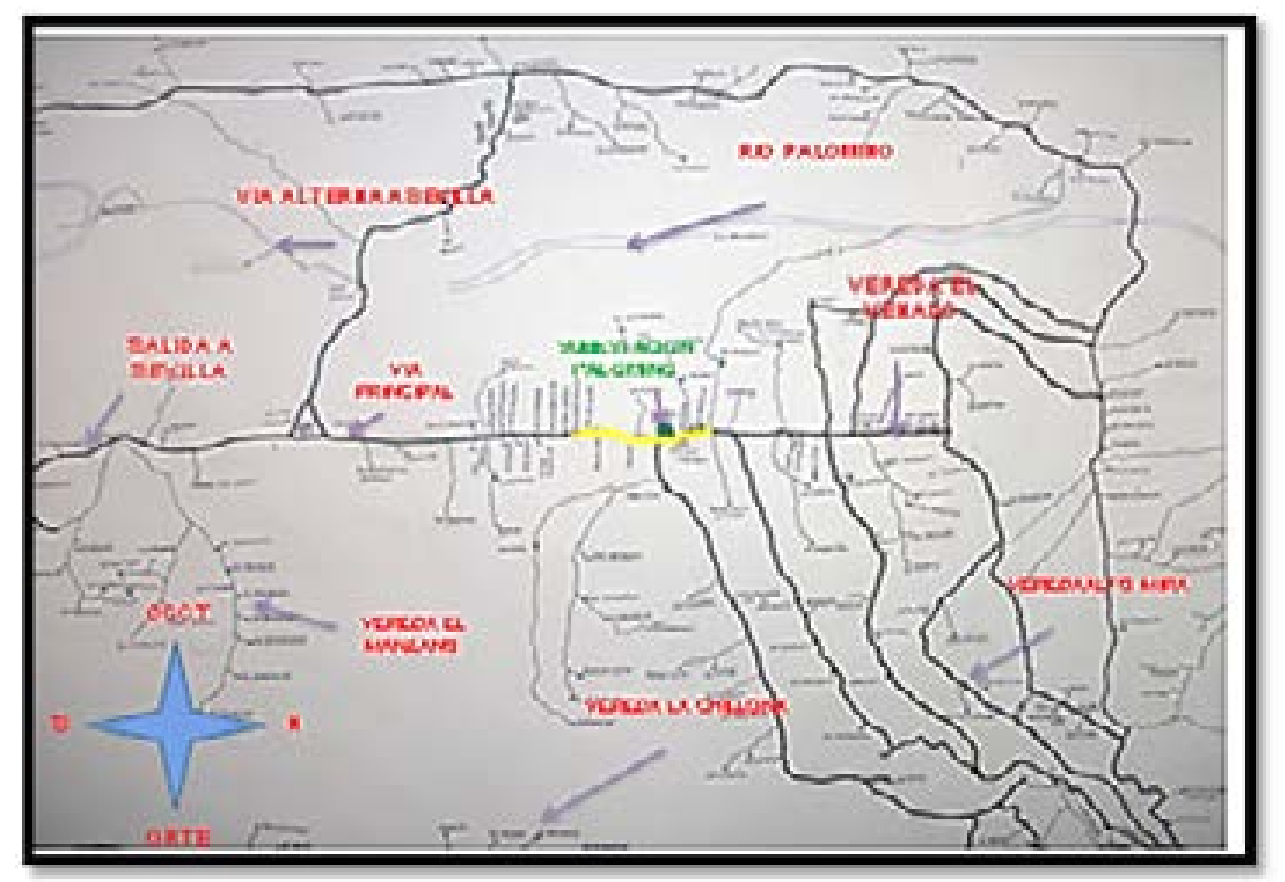

Figura 3, Georreferenciación corregimiento Palomino (Policía Nacional de Colombia, 2020)

El poblado se encuentra ubicado sobre la vía que de Sevilla conduce a la vereda el Venado a una distancia aproximada de 9 kilómetros, encontrando asentamientos residenciales en los costados de la vía. La generalidad del terreno es semi-ondulado y presenta un relieve montañoso que hace parte de las estribaciones de la cordillera central. La vía de acceso se encuentra pavimentada en su totalidad, sin embargo, se caracteriza por ser angosta, con curvas pronunciadas y su regular señalización.

El corregimiento por ser zona administrativa del Municipio de Sevilla, está regida por la alcaldía de ese municipio, distinguiéndose que no cuenta con Asambleas ni Concejos, tampoco cuenta con juzgados, fiscalías o entes de control ya que son manejados directamente desde el Municipio de Sevilla.
La revisión de los antecedentes relacionados con la implementación de la mediación policial, permiten concluir que este mecanismo es aplicado frecuentemente en el ámbito urbano, sin embargo, en el ámbito rural no se observa un nivel de implementación los suficientemente amplio para atender satisfactoriamente los conflictos que se presentan en esta comunidad, lo que implica un desacierto institucional que impacta negativamente en las condiciones de convivencia y seguridad de los habitantes del campo colombiano.

Los datos existentes en el Departamento Administrativo Nacional de Estadística (DANE), muestran que de la totalidad de los colombianos, el $7,1 \%$ de ellos habita en los centros poblados y $15,8 \%$ en el área rural dispersa, mientras que el restante está distribuido en cabeceras municipales $(77,1 \%)$, permitiendo visibilizar una 
aparente desatención del estado a más del $20 \%$ de la población colombiana cuando se trata de mecanismos formales para mediar sus conflictos (Departamento Administrativo Nacional de Estadística, 2018).

Para atender esta necesidad el grupo de investigación de la Escuela de Policía Gabriel González del Espinal - Tolima desarrolló una investigación en el año 2019, que permitió estructurar una Guía de Mediación Policial para el Sector Rural con el propósito de que los uniformados cuenten con una herramienta idónea al momento de pretender implementar estrategias para el fortalecimiento de la mediación policial en sus jurisdicciones rurales (Grupo de investigación ESGON, 2019).

Aunque la mencionada guía fue aceptada por la Dirección Nacional de Escuelas de la que los datos acogidos en su estructuración corresponden solamente a un sector rural del departamento del Tolima dejando una brecha importante, por cuanto se desconocen los resultados de su aplicabilidad en la totalidad de los sectores rurales del territorio colombiano, generándose consecuentemente el siguiente interrogante ¿Qué oportunidades o dificultades presenta la Guía para fortalecer la implementación de la mediación policial para el sector rural?

\section{MÉTODO}

Dado que se busca la validación práctica de la Guía de Mediación Policial para el Sector Rural para comprobar su aplicabilidad en un lugar diferente al de su elaboración, el presente trabajo será elaborado bajo el planteamiento metodológico mixto secuencial, teniendo en cuenta que se establece la misma importancia a la recolección y análisis de resultados cuantitativos y cualitativos. Adicionalmente se determina un alcance exploratorio del fenómeno de estudio que se relaciona con la aplicabilidad de la Guía para fortalecer la implementación de la mediación policial en el sector rural de Colombia (Hernández, Fernandez, \& Baptista, 2014, pág. 92).

Esta investigación mixta secuencial está compuesta por dos enfoques (cuantitativo y cualitativo). El enfoque cuantitativo se concibe como no experimental teniendo en cuenta que no se realizan manipulaciones al objeto de estudio (Hernández, Fernandez, \& Baptista, 2014, pág. 4). En ese sentido, el enfoque cuantitativo no experimental se establece como transversal, por cuanto la recolección de los datos se ejecuta en un único momento del estudio.

Por su parte el enfoque cualitativo corresponde al tipo fenomenológico teniendo en cuenta que se valora la percepción de los funcionarios de policía que intervienen en acciones de mediación policial en las comunidades seleccionadas, con el propósito de describir la experiencia respecto a la aplicabilidad de la mencionada guía y el nivel de competencias de los sujetos para desenvolverse en el marco del fenómeno de estudio (mediación policial).

De acuerdo a lo anterior, se establecieron tres fases de desarrollo, la primera tiene que ver con la valoración de los conflictos en cada una de las localidades seleccionadas, en la segunda fase se validan las condiciones generales de aplicabilidad de la Guía para fortalecer la implementación de la mediación policial en el sector rural de Colombia, mediante la recolección y análisis de información cualitativa fenomenológica y en la fase tres se concretan las acciones del diseño mixto secuencial para la integración de los datos y establecer las metainferencias del presente estudio que permitan el planteamiento de propuestas para mejorar la estructura general y la aplicabilidad de la guía en el contexto rural colombiano.

Desde el punto de vista de la pertinencia institucional de la investigación, se determina una alineación con el tema la mediación policial 
rural que corresponde a la línea de acciones del servicio de policía que establece el área del servicio de policía en el manual de Ciencia, tecnología e Innovación de la Policía Nacional de Colombia (Policía Nacional de Colombia, 2017).

\section{POBLACIÓN Y MUESTRA}

Se consideran las limitaciones evidenciadas durante el estudio en relación con la emergencia sanitaria mundial causada por el virus COVID-19 en donde se limitó la movilidad y libertad de reunión de las personas con el propósito de contener la propagación del mencionado virus en todo el territorio nacional, por este motivo se determinó una muestra dirigida que obedece a las características geográficas, la accesibilidad y la no afectación de las poblaciones por el mencionado virus.

De acuerdo a lo anterior, las unidades de muestreo corresponden a individuos residentes en dos poblaciones, la vereda de torres del municipio Popayán, en el departamento del Cauca; y el corregimiento Palomino del municipio de Sevilla en el departamento del Valle del Cauca.

La vereda de Torres, cuenta con una población de 2.046 habitantes del cual $13 \%$ son menores de edad y $9 \%$ adultos mayores, según fuente poblacional de la Policía Nacional.

El personal uniformado que se encuentra en la zona es el cuadrante 12 con un (01) comandante y seis (06) patrulleros quienes prestan el servicio de vigilancia para esa vereda y se apoya en el cuadrante 14 con seis (06) patrulleros del Centro de Atención Inmediata No 7 (CAI \#7) de Popayán.

Por su parte, el corregimiento Palomino (Sevilla - Valle del Cauca) tiene una población de 425 habitantes y el servicio de policía es prestado por la Subestación Palomino que cuenta con un total de cuatro (04) mandos ejecutivos y cuatro
(04) patrulleros.

El proceso de recopilación de los datos fue realizado por uniformados adscritos a las unidades de policía que tienen injerencia en cada una de las localidades establecidas logrando consolidar las siguientes cifras para cada caso:

Tabla 1, cantidad de encuestas aplicadas por localidad

\begin{tabular}{|c|c|}
\hline Lugar & $\begin{array}{c}\text { Número total de } \\
\text { encuestas aplicadas }\end{array}$ \\
\hline Vereda Torres & 124 \\
\hline $\begin{array}{c}\text { Corregimiento } \\
\text { palomino }\end{array}$ & 62 \\
\hline
\end{tabular}

En el aspecto cualitativo, la muestra corresponde a casos importantes que se relacionan con los funcionarios de policías involucrados en la atención de conflictos con acciones de mediación policías en las jurisdicciones seleccionadas, los cuales se relacionan en la siguiente tabla.

Tabla 2, Funcionarios de policía seleccionados para la muestra de casos importantes por localidad

\begin{tabular}{|c|c|}
\hline Lugar & Funcionarios seleccionado \\
\hline Vereda Torres & $\begin{array}{c}\text { Un Intendente y un } \\
\text { Patrullero, }\end{array}$ \\
\hline $\begin{array}{c}\text { Corregimiento } \\
\text { palomino }\end{array}$ & Un Patrullero \\
\hline
\end{tabular}

Para la recolección de la información se empleó el instrumento validado en la guía de mediación que está compuesto por dos secciones, la primera sección que busca conocer los datos del encuestado, mientras la segunda sección incluye un total de preguntas generales relacionadas con el tema de estudio (mediación policial). Las respuestas incluidas en el instrumento son de tipo cerrado para las preguntas número $11,12,14$ y 15 , mientras que las preguntas número 1, 3, 613 conciben selección de respuestas estructuradas mediante la escala de Likert (Llauradó, 2014). Las demás 
preguntas $(2,4,5,7,8,9$ y 10$)$ establecen preguntas de única selección en relación con las causas y comportamientos de los encuestados frente a los conflictos.

Para el componente cualitativo, se estableció un diario de campo por parte de los investigadores como instrumento para el seguimiento del estudio en el que se registran los hechos susceptibles de ser interpretados y analizados como parte de los datos allegados al estudio. Adicionalmente se determinó un formato de entrevista semiestructurada con preguntas generales relacionadas con el fenómeno de estudio y las características de oportunidad o dificultad de la Guía para fortalecer la implementación de la mediación policial para el sector rural.

Esta entrevista semiestructurada incluye los datos sociodemográficos y un total de doce (12) preguntas de respuesta abierta, la cual fue validada mediante arbitraje de investigadores expertos que integran el grupo de investigación de la Escuela de Policía Gabriel González, determinando que su aplicación será mediante la herramienta en línea Meet de la Gsuite de Google (Google Inc, 2020) y propendiendo por su rigurosidad mediante la consistencia lógica con aplicación de la totalidad del cuestionario validado en las mismas condiciones a los expertos seleccionados en cada una de los lugares donde se ejecuta el estudio, adicionalmente se incluyó una auditoria externa por parte de una investigadora experta en el tema quien evaluó permanentemente el diario de campo, las categorías generadas y el procedimiento para generar la teoría fundamentada.

Para la tabulación y procesamiento de los datos cuantitativos se empleó la herramienta ofimática Excel, teniendo en cuenta su fortaleza en cuanto a la aplicación de fórmulas y la generación de gráficas dinámicas que incluyeron los resultados consolidados de datos.

Se crearon dos hojas de Excel debidamente formuladas para que contabilicen los datos allegados en cada una de las encuestas, los cuales fueron digitados por los investigadores. Para relacionar los resultados y preferencias para cada una de las respuestas se empleó la siguiente codificación:

Tabla 3: Codificación de escala para las preguntas $11,12,14$ y 15

\begin{tabular}{|c|c|}
\hline NÚMERO & CRITERIO \\
\hline 0 & Respuesta negativa “NO" \\
\hline 1 & Respuesta afirmativa "SI" \\
\hline
\end{tabular}

Para determinar el nivel de aceptabilidad de los encuestados frente al objeto de actitud: medicación policial brindado por la Policía Nacional de Colombia, se estableció que el índice de valoración corresponde a la relación entre la sumatoria total de respuestas afirmativas y la totalidad de encuestas recolectas.

El segundo objeto de actitud asumido en el presente estudio corresponde a los conflictos en la comunidad, para este propósito se establece la siguiente codificación para determinar el índice de probabilidad de ocurrencia. 
Tabla 4: lista de preguntas relacionadas con el objeto de actitud:

conflictos en la comunidad.

\begin{tabular}{|c|c|c|c|c|}
\hline \multirow{2}{*}{ No. } & \multirow{2}{*}{ Pregunta } & \multirow{2}{*}{ Dirección } & \multicolumn{2}{|c|}{ Codificación } \\
\hline & & & Valoraciones & Número \\
\hline 1. & $\begin{array}{l}\text { ¿Entre los miembros de su } \\
\text { comunidad se presentan } \\
\text { conflictos o agresiones? }\end{array}$ & $\begin{array}{c}\text { Más } \\
\text { probabilidad }\end{array}$ & $\begin{array}{l}\text { A. Siempre } \\
\text { B. Casi siempre } \\
\text { C. Pocas veces } \\
\text { D. Nunca }\end{array}$ & $\begin{array}{l}4 \\
3 \\
2 \\
1\end{array}$ \\
\hline 3. & $\begin{array}{l}\text { ¿En su comunidad se generan } \\
\text { insultos, ofensas o peleas? }\end{array}$ & $\begin{array}{c}\text { Más } \\
\text { probabilidad }\end{array}$ & $\begin{array}{l}\text { A. Siempre } \\
\text { B. Casi siempre } \\
\text { C. Pocas veces } \\
\text { D. Nunca }\end{array}$ & $\begin{array}{l}4 \\
3 \\
2 \\
1\end{array}$ \\
\hline 6. & $\begin{array}{l}\text { ¿Cuándo se presenta un } \\
\text { conflicto se da la oportunidad } \\
\text { para hablar y solucionar la } \\
\text { situación? }\end{array}$ & $\begin{array}{l}\text { Menos } \\
\text { probabilidad }\end{array}$ & $\begin{array}{l}\text { A. Siempre } \\
\text { B. Casi siempre } \\
\text { C. Pocas veces } \\
\text { D. Nunca }\end{array}$ & $\begin{array}{l}1 \\
2 \\
3 \\
4\end{array}$ \\
\hline 13. & $\begin{array}{l}\text { ¿Tiene conocimiento básico } \\
\text { sobre la mediación policial } \\
\text { para resolución de conflictos? }\end{array}$ & $\begin{array}{c}\text { Menos } \\
\text { probabilidad }\end{array}$ & $\begin{array}{l}\text { A Tengo mucho } \\
\text { conocimiento } \\
\text { B Tengo conocimiento } \\
\text { C Desconozco si tengo } \\
\text { conocimiento } \\
\text { D Tengo poco } \\
\text { conocimiento } \\
\text { E No tengo conocimiento }\end{array}$ & $\begin{array}{l}1 \\
2 \\
3 \\
4\end{array}$ \\
\hline
\end{tabular}

La codificación de cada valoración aplicable a las preguntas con direccionamiento: más probabilidad, establece el número de mayor denominación (4) para la categoría "siempre" y el número de menor denominación (1) para la categoría "nunca". Para el caso de las preguntas con direccionamiento: menos probabilidad, se invierte la asignación del número y la categoría. Para la pregunta 13 se asigna el número de menor denominación (1) para la categoría "Tengo mucho conocimiento y consecuentemente se asigna el número de mayor denominación (5) para la categoría "No tengo conocimiento" por tratarse de una pregunta con direccionamiento a menos probabilidad. 
Ahora bien, las preguntas $2,4,5,7,8,9$ y 10 se relacionan con un objeto de actitud específico que prioriza las respuestas, por este motivo se determina asigna el número uno (1) para la respuesta seleccionada por el encuestado y el número cero (0) para el caso contrario, de esta manera su valoración corresponde con la sumatoria total para cada respuesta seleccionada, indicando que la mayor priorización corresponde proporcionalmente con la sumatoria mayor.

A continuación, se relacionan los objetos de actitud valoradas en cada pregunta.

Tabla 5, relación de objetos de actitud valorados en preguntas de única selección

\begin{tabular}{|c|c|c|}
\hline No. & Pregunta & Objeto de actitud valorado \\
\hline 2. & $\begin{array}{l}\text { ¿Los conflictos o agresiones que se presentan } \\
\text { dentro y fuera de la vereda son ocasionados por? }\end{array}$ & $\begin{array}{l}\text { Causas individuales de los } \\
\text { conflictos }\end{array}$ \\
\hline 4. & Alguna persona de su comunidad hace amenazas: & Tipos de amenazas \\
\hline 5. & $\begin{array}{l}\text { Los conflictos o agresiones entre los miembros de } \\
\text { su comunidad se dan por: }\end{array}$ & Causas colectivas de los conflictos \\
\hline 7. & $\begin{array}{l}\text { En el momento en el que se presenta un conflicto } \\
\text { su reacción inmediata es: }\end{array}$ & $\begin{array}{l}\text { Reacción individual ante un } \\
\text { conflicto }\end{array}$ \\
\hline 8. & $\begin{array}{l}\text { Cuando tiene conflictos con las autoridades de su } \\
\text { comunidad acude a: }\end{array}$ & $\begin{array}{l}\text { Reacción individual ante un } \\
\text { conflicto con autoridades }\end{array}$ \\
\hline 9. & $\begin{array}{l}\text { Cuando tiene conflictos con los miembros más } \\
\text { antiguos de su comunidad usted acude a: }\end{array}$ & $\begin{array}{l}\text { Reacción individual ante un } \\
\text { conflicto con miembros más } \\
\text { antiguos }\end{array}$ \\
\hline 10. & $\begin{array}{l}\text { Cuando tiene conflictos con sus familiares usted } \\
\text { acude a: }\end{array}$ & $\begin{array}{l}\text { Reacción individual ante un } \\
\text { conflicto con familiares }\end{array}$ \\
\hline
\end{tabular}

El procesamiento de los datos cualitativos se fundamenta en la valoración desde la experiencia en la ejecución del proceso de mediación policial que ejecutan los funcionarios en cada una de las localidades rurales donde labora a partir de la categorización de los datos obtenidos en las entrevistas semiestructuradas y en la observación de los investigadores consignada en el diario de campo para generar la teoría fundamentada desde las categorías de análisis evidenciadas.
La organización de los datos cualitativos obedece a los criterios de persona entrevistada, posteriormente se prepararon los datos recolectados de las entrevistas mediante la transcripción en documento de Word (office) por parte de los investigadores y finalmente se ejecutó la exhaustiva labor de descubrimiento de las unidades de análisis y la agrupación mediante técnicas de escrutinio y de corte y clasificación de expresiones o segmentos de texto, entre los siguientes temas y categorías: 
Tabla 6, temas y categorías establecidas en el análisis cualitativo

\begin{tabular}{|c|c|}
\hline Tema & Categoría \\
\hline \multirow{4}{*}{$\begin{array}{c}\text { Opinión sobre la mediación } \\
\text { policial }\end{array}$} & Aporte de la mediación a la seguridad y convivencia \\
\cline { 2 - 2 } & Procedimiento para ejecutar la mediación policial \\
\hline \multirow{4}{*}{\begin{tabular}{c} 
Condiciones generales de la guía \\
\cline { 2 - 2 }
\end{tabular}} & Presentación y estilo de la guía. \\
\cline { 2 - 2 } & Suficiencia y pertinencia del módulo 1 \\
\cline { 2 - 2 } & Suficiencia y pertinencia del módulo 2 \\
\cline { 2 - 2 } & Suficiencia y pertinencia del módulo 3 \\
\cline { 2 - 2 } & Suficiencia y pertinencia del módulo 4 \\
\cline { 2 - 2 } & Utilidad de la guía \\
\hline
\end{tabular}

El análisis e interpretación de los resultados para el estudio mixto consiste en establecer metainferencias a partir de las inferencias alcanzadas en la fase uno y dos, de tal manera que permitan la validación de la Guía para fortalecer la implementación de la mediación policial para el sector rural desde el punto de vista de las oportunidades y debilidades.

\section{RESULTADOS}

\section{Resultados fase cuantitativa de valoración de conflictos}

Los resultados se presentan en dos secciones, la primera se relaciona con los datos de la vereda de Torres (Cauca) y la segunda sección corresponde a los datos del corregimiento Palomino (Valle del Cauca).

\section{Vereda de Torres (Cauca)}

Para el caso de la vereda de Torres se conformó una muestra de ciento veinticuatro ciudadanos (124) y se caracterizó porque el promedio de edad de los ciudadanos encuestados en la vereda de Torres es de 37 años aproximadamente, además la edad más recurrente de ciudadanos encuestados es de 41 años. La desviación estándar indica que la mayor cantidad de ciudadanos encuestados tiene una edad entre 24 años y 50 años (relación de la media y desviación estándar), lo cual permite inferir que la muestra acogida tiene una representatividad suficiente de personas ubicada en el grupo etario adulto y adulto de mediana edad (Hogg \& Vaughan, 2010, pág. 577).

Los resultados relacionados con el objeto de actitud: conflictos con la comunidad, muestran que la mayoría de los ciudadanos encuestados (59\%) consideran que en la vereda de Torres siempre se presentan conflictos o agresiones y el $15 \%$ de los ciudadanos involucrados en la muestra manifiestan que casi siempre ocurren conflictos. El anterior resultado se confirma por parte de los ciudadanos cuando contestan en su mayoría que siempre (40\%) o casi siempre $(38 \%)$ se generan insultos en su comunidad.

Ahora bien, el $52 \%$ de los ciudadanos encuestados manifestaron que casi siempre se da la oportunidad para hablar y solucionar los conflictos, mientras que el $31 \%$ de la muestra manifiesta que siempre se da la oportunidad. Frente a la pregunta relacionada con el conocimiento básico sobre la mediación policial para la resolución de conflictos, 70 ciudadanos contestaron que tienen mucho conocimiento y 17 más contestaron que tienen conocimiento.

Cuando se les pregunto a los ciudadanos involucrado en la muestra sobre las causas individuales que generan conflictos, se encontró que 63 encuestados se lo atribuyen a los chismes y comentarios mal intencionados, mientras que 
32 personas consideran que son causados por problemas familiares y violencia intrafamiliar, constituyéndose estas dos causas como las más recurrentes. Otra de las preguntas muestra que 54 encuestados afirmaron que las amenazas en su comunidad se realizan con armas, mientras que 33 personas manifiestan que las amenazas son de tipo verbal.

Cincuenta (50) de los encuestados consideran que las causas colectivas de los conflictos tienen que ver con la exclusión de personas de la comunidad y 38 ciudadanos manifiestan que la causa obedece a la falta de acuerdo. Por su parte 29 personas se lo atribuyen a la falta de respecto y autoridad. Siete (07) encuestado manifestaron otras causas generados de conflictos con el exceso de consumo de bebidas embriagantes (2) y tres de estas personas manifestaron que la vereda de Torres es muy tranquila.

La reacción individual de los encuestados frente a un conflicto se manifiesta en su mayoría mediante el dialogo con entre las partes involucradas (68 respuestas), mientras que 45 ciudadanos manifiestan que reacción mediante agresiones físicas y verbales y solamente cuatro (04) de los encuestados acuden ante una autoridad.

Cinco (05) encuestados manifestaron que reaccionan ante un conflicto mediante el llamado a la Policía Nacional, mientras que dos (02) ciudadanos manifestaron que no tienen conflictos.

Cuando se les preguntó a los encuestados sobre su reacción ante conflictos con las autoridades presentes la comunidad, 60 de ellos manifestaron que acuden al dialogo directos, 41 ciudadanos acuden a agresiones físicas y verbales, 11 personas acuden ante una autoridad institucional y solamente 12 ciudadanos manifestaron que no tiene conflictos con autoridades.
La reacción individual generalizada entre los encuestados ante una situación de conflicto con personas más antiguas de su comunidad, tiene que ver con el dialogo directo con la otra parte (73 respuestas), mientras que 26 ciudadanos acuden a las agresiones físicas y verbales. Quince (15) de los encuestados manifestaron que no tienen conflictos con personas más antiguas de su comunidad, otros nueve (09) acuden ante una autoridad y solamente una persona acudiría a la patrulla del cuadrante de policía como reacción ante conflictos con personas más antiguas de la verdad de Torres.

Frente a la reacción de los ciudadanos encuestados ante conflictos con sus familiares, 77 de ellos manifestaron que acuden al dialogo directo con la otra parte, mientras que otros 23 ciudadanos acuden a las agresiones físicas. 18 encuestados manifestaron que no tienen conflictos con sus familiares y solamente 6 personas acuden ante una autoridad institucional cuando se generan conflictos con sus familiares.

Los resultados frente a la aceptabilidad de la mediación policial ejercida por la Policía Nacional arrojan que la mayoría de los encuestados (94\%) manifestaron que si acudirían a un mecanismo de mediación policial para solucionar sus conflictos, además, el $76 \%$ de las personas encuestadas manifestó que ha practicado la mediación policial por medio de un tercero neutral cuando ha necesitado resolver un conflicto.

Cuando se les preguntó a los encuestados si la Policía Nacional le brinda conocimiento sobre la mediación policial, el $78 \%$ de ellos manifestaron que sí lo proporcionan, mientras que el $22 \%$ manifestó lo contrario. Ante la pregunta relacionada con la probabilidad de uso de la oficina de mediación policial, la mayoría de los encuestados (97\%) manifestaron que si acudirian ante estas oficinas para dirimir sus conflictos. 
Los resultados de la encuesta en relación con el objeto de actitud: conflictos con la comunidad, llama la atención el hecho de que la mayoría de los ciudadanos manifestó la ocurrencia de conflicto en la vereda de Torres, lo cual resalta la importancia de la implementación de los mecanismos de mediación policial en esa jurisdicción.

Este mecanismo de mediación policial probablemente tiene un alto nivel de efectividad en su aplicación si se tiene en cuenta la mayoría de los encuestados manifestó que recurre al diálogo para solucionar sus conflictos y que si conocen sobre la mediación policial. También se destaca que los encuestados muestran una tendencia mayor a emplear el dialogo cuando la contraparte corresponde a miembros más antiguos o a familiares, situación que no acurre cuando se trata de conflictos con autoridades.

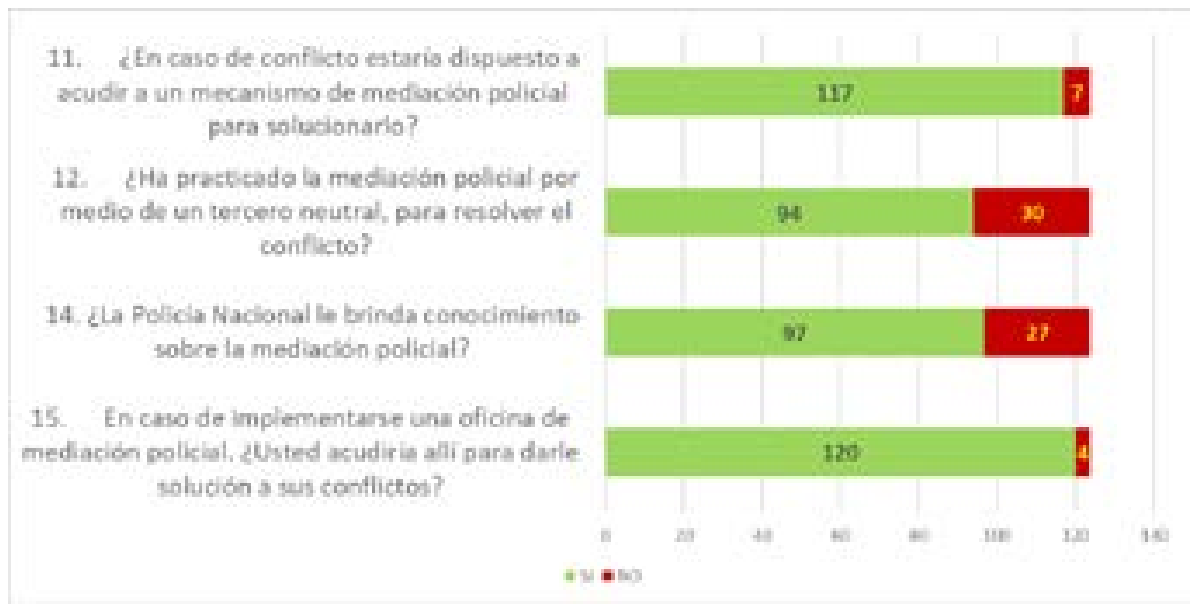

Figura 4, Comparativo datos asociados a la aceptabilidad de la mediación policial Vereda de Torres

Cuando se realizó la valoración de probabilidad de ocurrencia de conflictos en la vereda de Torres se encuentran los siguientes resultados:

Tabla 7, Datos estadísticos de valoración de probabilidad de ocurrencia de conflictos

\begin{tabular}{|c|c|}
\hline Dato estadístico & Valor \\
\hline Media & 10,42741935 \\
\hline Error típico & 0,144473046 \\
\hline Mediana & 10 \\
\hline Moda & 10 \\
\hline Rango & 10 \\
\hline Mínimo & 5 \\
\hline Máximo & 15 \\
\hline Cuenta & 124 \\
\hline
\end{tabular}


Los anteriores datos descriptivos sobre la valoración de la probabilidad de ocurrencia de conflictos en la comunidad de la vereda de Torres, se confirma que el valor promedio está en 10.42, lo cual se ubica en el tercer cuartil de probabilidad dentro del rango como se muestra en la siguiente tabla.

Tabla 8, valoración de probabilidad de ocurrencia de conflictos en la vereda de Torres

\begin{tabular}{|c|c|c|c|c|}
\hline $\begin{array}{c}\text { Probabilidad de } \\
\text { ocurrencia }\end{array}$ & $\begin{array}{c}\text { Cuartil 1 Menos } \\
\text { probabilidad }\end{array}$ & Cuartil 2 & Cuartil 3 & Cuartil 4 \\
\hline Rango & $4-6$ & $7-9$ & $10-12$ & $13-15$ \\
\hline $\begin{array}{c}\text { Ubicación de la } \\
\text { media }\end{array}$ & & & 10,42 & \\
\hline $\begin{array}{c}\text { Ubicación de la } \\
\text { mediana }\end{array}$ & & & 10 & \\
\hline $\begin{array}{c}\text { Ubicación de la } \\
\text { moda }\end{array}$ & & & 10 & \\
\hline
\end{tabular}

Esta probabilidad de ocurrencia se afirma aún más cuando se verifica que el valor de las medidas de centralidad: mediana y moda, también se ubican en el tercer cuartil (10), indicando además una simetría de los datos. En ese sentido se puede inferir que la probabilidad de ocurrencia de los conflictos en la vereda de Torres esta entre el $58 \%$ y el $66 \%$ aproximadamente.

Por otra parte, la mayoría de los encuestados le atribuyen la causa de los conflictos a los chismes y comentarios mal intencionados y que además se generan amenazas en su mayoría con el uso de armas o con agresiones verbales, permitiendo inferir un alto nivel de agresividad que se constituye en una causa importante que puede desencadenar situaciones como lesiones personales o homicidios entre los ciudadanos.

\section{Corregimiento Palomino (Valle del cauca)}

Para el caso del corregimiento Palomino, los ciudadanos involucrados en la muestra tienen una edad promedio de 35 años y el rango de edad de la totalidad de los encuestados oscila entre los 15 y los 69 años de edad, significando una representatividad de personas que comprende los grupos etarios joven, adulto joven, adulto, adulto de mediana edad y anciano (Hogg \& Vaughan, 2010).

La consolidación de los resultados sobre el objeto de actitud: conflictos con la comunidad, arrojan que el $55 \%$ de los encuestados manifestaron que casi siempre se presentan conflictos o agresiones y el 16\% contestó que siempre se presentan.

Adicionalmente se observa que el $58 \%$ de los ciudadanos que contestaron la encuesta manifiesta que casi siempre se generan insultos, ofensas o peleas, en contraste, el $18 \%$ de la muestra confirmó que nunca se presentan.

Adicionalmente el $50 \%$ de los ciudadanos encuestados confirman que casi siempre acuden al dialogo para solucionar una situación de conflicto, mientras que otro $26 \%$ afirma que nunca se da la oportunidad para dialogar. 
Cuando se les preguntó a los habitantes del corregimiento Palomino involucrado en la muestra sobre el conocimiento básico frente a la mediación policial, 24 manifestaron que tienen poco conocimiento y otros 17 confirmaron que no tienen conocimiento al respecto. Solamente 16 personas manifestaron que tienen conocimiento y un (01) ciudadano dijo que tenía mucho conocimiento.

Los resultados de la pregunta relacionada con el objeto de actitud: causas individuales del conflicto, muestran que 34 personas le atribuyen la generación conflictos a los chismes y comentarios mal intencionados, por su parte 9 ciudadanos manifestaron que la causa obedece a problemas familiares y violencia intrafamiliar $u$ otro tanto considera que la razón de los conflictos dentro y fuera de la vereda es causado por la exclusión de ciertos miembros de la comunidad.

En el objeto de actitud: tipos de amenazas, 23 ciudadanos del corregimiento Palomino que se vincularon a la muestra manifestaron que las amenazas se ejecutan en cualquiera de las opciones presentadas en las respuestas, mientras que 18 personas confirman que las amenazas son físicas y 10 más consideran que son de tipo verbal.

Frente a la pregunta relacionada con las causas colectivas de los conflictos, 27 de los ciudadanos que contestaron la encuesta se lo atribuyen a la falta de respeto y autoridad, además otros 20 ciudadanos dijeron que se debe a la falta de acuerdos y un grupo de 14 personas confirman que las causas colectivas de conflictos están relacionadas con la exclusión de personas. La valoración de las reacciones frente a los conflictos por parte de la muestra de ciudadanos del corregimiento Palomino, evidencia que 44 personas manifiestan reaccionar con agresiones físicas y verbales, mientras que otras 18 reaccionan mediante dialogo con quien se tuvo el conflicto.
La valoración de la reacción individual de los ciudadanos involucrados en la muestra cuando se enfrentan a conflictos con autoridades permite visibilizar que un grupo de 19 personas ejecuta agresiones físicas o verbales, otros 18 encuestados acuden al dialogo directo, 14 dicen que acuden a autoridades institucionales y los 11 ciudadanos restantes manifiestan que no tienen conflictos con autoridades.

La reacción que la muestra de ciudadanos del corregimiento Palomino toma frente a conflictos con miembros más antiguos de su comunidad exponen que un grupo de 18 personas ejecuta agresiones físicas o verbales, otro grupo de 22 habitantes acude al dialogo directo con la otra parte, mientras que 11 ciudadanos confirman que acuden a una autoridad institucional y otro tanto dice que no tiene conflictos con miembros más antiguos de su comunidad.

La reacción de los encuestados frente a los conflictos con familiares muestra que 21 de ellos acuden a dialogo directo con la otra parte, otros 19 manifiesta que no tiene conflictos con sus familiares, un grupo de 12 ciudadanos acude a las agresiones físicas y verbales y 10 personas acuden ante una autoridad institucional.

La valoración del objeto de actitud: aceptabilidad de la mediación policial ejercido por la Policía Nacional, por parte de los encuestados del corregimiento Palomino, muestra que la mayoría de ellos (95\%) si acudiría a un mecanismo de este tipo para solucionar sus conflictos. Cuando se les preguntó a los ciudadanos si ha practicado la mediación policial por medio de terceros neutrales, el $74 \%$ de la muestra manifestó que si lo ha hecho y un $26 \%$ manifestó lo contrario. Por su parte el $74 \%$ de los encuestados manifestó que la Policía Nacional sí proporciona conocimiento sobre la mediación policial y el 26 $\%$ restante dijo que no le brindan conocimiento al respecto. El $94 \%$ de los ciudadanos del corregimiento Palomino que participaron en la muestra manifestaron que sí harían uso de la 
oficina de mediación policial para solucionar sus conflictos y solamente un $6 \%$ dijo que no lo haría.

La valoración del objeto de actitud: conflictos con la comunidad, por parte de las personas involucradas en la encuesta realizada en el corregimiento Palomino permite visibilizar que, aunque consideran que casi siempre se presentan conflictos, en todo caso al comparar con los resultados de la valoración realizada en la vereda de Torres, la tendencia es superior en el corregimiento Palomino. Esta inferencia se fundamenta en la revisión de los resultados codificados en relación con las respuestas 1 , 3,6 y 13 relacionadas con la probabilidad de ocurrencia de conflictos, como se observa en la siguiente tabla.

Tabla 9, Datos estadísticos de valoración de probabilidad de ocurrencia de conflictos

\begin{tabular}{|c|c|}
\hline Dato estadístico & Valor \\
\hline Media & 11,77419355 \\
\hline Error típico & 0,268591479 \\
\hline Mediana & 12 \\
\hline Moda & 12 \\
\hline Rango & 8 \\
\hline Mínimo & 7 \\
\hline Máximo & 15 \\
\hline Cuenta & 62 \\
\hline
\end{tabular}

Cuando se realiza el posicionamiento de las medidas estadísticas: moda, mediana y media, se observa que, aunque la probabilidad de ocurrencia se ubica en el tercer cuartil, los datos se ubican más próximos al límite superior de ese rango, indiciando entonces una mayor probabilidad que estaría entre el $66 \%$ y el $75 \%$ aproximadamente.

Tabla 10, valoración de probabilidad de ocurrencia de conflictos corregimiento Palomino

\begin{tabular}{|c|c|c|c|c|}
\hline $\begin{array}{c}\text { Probabilidad de } \\
\text { ocurrencia }\end{array}$ & $\begin{array}{c}\text { Cuartil 1 Menos } \\
\text { probabilidad }\end{array}$ & Cuartil 2 & Cuartil 3 & Cuartil 4 \\
\hline Rango & $4-6$ & $7-9$ & $10-12$ & $13-15$ \\
\hline $\begin{array}{c}\text { Ubicación de la } \\
\text { media }\end{array}$ & & & 11,77 & \\
\hline $\begin{array}{c}\text { Ubicación de la } \\
\text { mediana }\end{array}$ & & 12 & 12 & \\
\hline $\begin{array}{c}\text { Ubicación de la } \\
\text { moda }\end{array}$ & & & & \\
\hline
\end{tabular}

Continuando con el análisis de los resultados del corregimiento Palomino, también se evidencia que la muestra de ciudadanos le atribuye la mayoría de los conflictos a los chismes y comentarios mal intencionados, además que las amenazas también involucran formas verbales, armas, agresiones físicas y como agravante los ciudadanos manifiestan que estos conflictos son causados por la falta de respecto y autoridad, lo cual permite inferir que para el caso del corregimiento Palomino existe un aparente falta de cobertura de las instituciones del estado para atender la situaciones conflicto.

El análisis de las reacciones de los ciudadanos del corregimiento Palomino arroja que existe 
una preferencia para reaccionar con agresiones físicas que se mantiene cuando la contraparte corresponde a autoridades de la comunidad y que disminuye cuando se trata de conflictos con miembros más antiguos de la comunidad. Respecto de las reacciones ante conflictos con familiares predomina el dialogo directo con la otra parte. Estos resultados muestran que la muestra de ciudadanos reconoce y respecta menos a las autoridades de su comunidad en contraste con los resultados de la Vereda de Torres.

Por otra parte, la mayoría de los encuestados manifestó que haría uso de los mecanismos de mediación policial para solucionar sus conflictos, sin embargo, no han practicado la mediación policial por medio de terceros neutrales. Este resultado contrasta con lo evidenciado en la vereda torres donde la mayoría de los involucrados en la muestra manifestaron que si han practicado la mediación policial por medio de terceros.

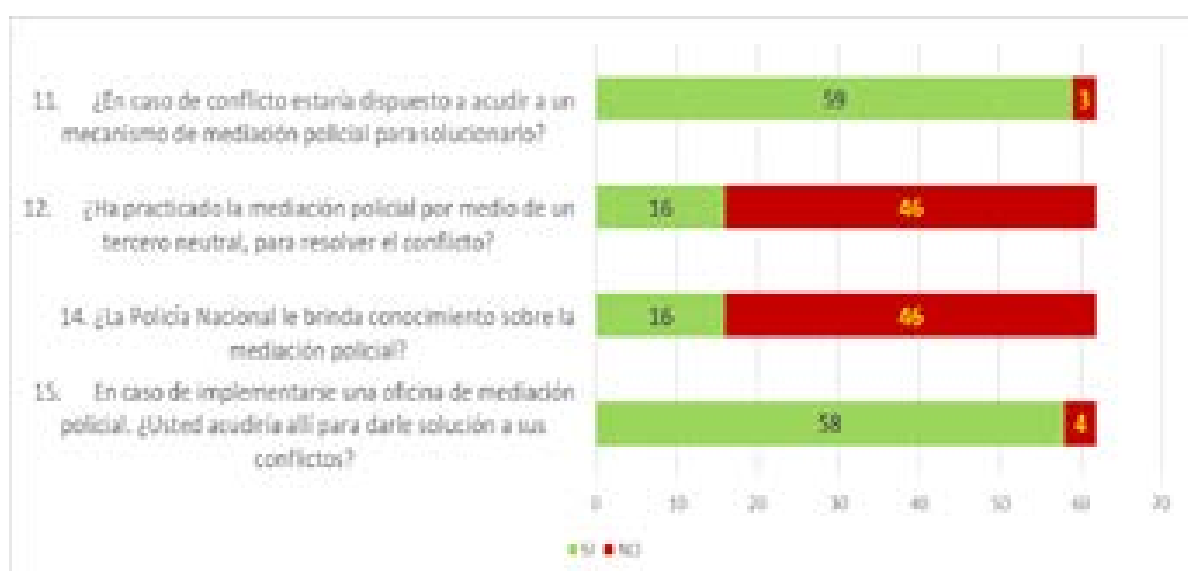

Figura 5, Comparativo datos asociados a la aceptabilidad de la mediación policial Corregimiento Palomino

Los datos relacionados con el conocimiento que brinda la Policía Nacional sobre la mediación policial a los ciudadanos muestra que en su mayoría no ha recibido información al respecto, contrastando con los resultados de la vereda Torres en donde los ciudadanos manifestó que si han recibido conocimiento por parte de la institución.

\section{RESULTADOS FASE CUALITATIVA DE VALIDACIÓN DE CONDICIONES DE LA GUÍA}

A continuación, se relacionan los datos sociodemográficos de las entrevistas semiestructuradas aplicadas a los expertos que ejecutan el proceso de mediación policial en cada una de las jurisdicciones seleccionadas en el estudio. 
Tabla 11, datos sociodemográficos entrevista a expertos

\begin{tabular}{|c|c|c|c|}
\hline Item & $\begin{array}{l}\text { Experto 1: vereda de } \\
\text { Torres (Cauca) }\end{array}$ & $\begin{array}{c}\text { Experto 2: } \\
\text { corregimiento } \\
\text { palomino (Valle del } \\
\text { Cauca) }\end{array}$ & $\begin{array}{l}\text { Experto 3: corregimiento } \\
\text { palomino (Valle del Cauca) }\end{array}$ \\
\hline $\begin{array}{l}\text { Fecha de la } \\
\text { entrevista: }\end{array}$ & $09-08-2020$ & $09-08-2020$ & $09-08-2020$ \\
\hline $\begin{array}{c}\text { Medio de } \\
\text { comunicación: }\end{array}$ & Meet (Google) & Meet (Google) & Meet (Google) \\
\hline Edad (años): & 40 & 29 & 28 \\
\hline Genero: & Masculino & Masculino & Masculino \\
\hline $\begin{array}{l}\text { Entidad donde } \\
\text { labora: }\end{array}$ & Policía Nacional & Policía Nacional & Policía Nacional \\
\hline $\begin{array}{c}\text { Cargo que } \\
\text { desempeña: }\end{array}$ & $\begin{array}{l}\text { Intendente - Supervisor del } \\
\text { servicio (Mediador Policial) }\end{array}$ & $\begin{array}{l}\text { Secretario subestación } \\
\text { Palomino }\end{array}$ & $\begin{array}{l}\text { Patrullero - Auxiliar de } \\
\text { información (Mediador } \\
\text { Policial) }\end{array}$ \\
\hline
\end{tabular}

Los resultados sobre la opinión de los expertos frente a la mediación policial, se sintetizan en la siguiente tabla que se estructura teniendo en cuenta los temas y categorías identificadas.

Tabla 12, categorías asociadas al tema: opinión sobre la mediación policial

\begin{tabular}{|c|c|c|c|}
\hline Categoría & Experto 1 & Experto 2 & Experto 3 \\
\hline $\begin{array}{l}\text { Aporte de la } \\
\text { mediación } \\
\text { policial a la } \\
\text { seguridad y } \\
\text { convivencia }\end{array}$ & $\begin{array}{l}\text { “...se ha logrado mayor } \\
\text { acercamiento a la } \\
\text { comunidad..." } \\
\text { “...disminuyendo los } \\
\text { conflictos..." }\end{array}$ & $\begin{array}{l}\text { “...Es un medio eficaz } \\
\text { donde se erradica o se } \\
\text { mengua los conflictos... } \\
\text { “ }\end{array}$ & $\begin{array}{c}\text { “...Su aporte a la seguridad } \\
\text { es vital, ya que, si se } \\
\text { erradica actos contrarios } \\
\text { a la convivencia, se } \\
\text { logra eliminar la posible } \\
\text { materialización de } \\
\text { delitos..." }\end{array}$ \\
\hline $\begin{array}{l}\text { Procedimiento } \\
\text { para ejecutar } \\
\text { la mediación } \\
\text { policial }\end{array}$ & $\begin{array}{l}\text { “...mediación policial } \\
\text { en Estación de Policía y } \\
\text { mediación en in Situ...” } \\
\text { “en caso de no llegar a un } \\
\text { acuerdo... proceso verbal } \\
\text { inmediato estipulado en el } \\
\text { art, } 222 \text { del CNPC...” }\end{array}$ & $\begin{array}{l}\text { “...Actualmente es un } \\
\text { poco complejo... por el } \\
\text { tema de COVID-19...” } \\
\text { “...se puede hacer en } \\
\text { el sitio o se les hace la } \\
\text { invitación a mediar en } \\
\text { la estación Sevilla...” }\end{array}$ & $\begin{array}{l}\text { "...es de forma presencial } \\
\text { mediante campañas } \\
\text { que eduquen a toda la } \\
\text { comunidad, de esta forma } \\
\text { logrando despejar dudas y } \\
\text { preguntas que se generen a } \\
\text { raíz de la norma..." }\end{array}$ \\
\hline
\end{tabular}

Los resultados consolidados desde las entrevistas de los expertos, permiten inferir que la mediación policial aporta significativamente a las condiciones de seguridad y convivencia en las localidades involucradas en el estudio y que este medio inmaterial tiene un alto nivel de aceptación por parte de las personas que se involucraron en el estudio por cuanto en su mayoría harían uso de la mediación policial para la resolución de sus conflictos.

Por otra parte, los resultados muestran que los uniformados entrevistados en su generalidad tienen arraigado el procedimiento estándar establecido en la guía 1PR-GU-004 distinguiéndose la particularidad de que la mediación se ejecuta en sitio y en la estación de policía, sin embargo, los funcionarios del corregimiento Palomino expresan que la práctica 
de la mediación policial actualmente presenta inconvenientes para su aplicación debido a la situación actual de emergencia nacional (Covid-19) atribuyéndole la mayoría de las acciones de mediación policial a las campañas de divulgación que ejecutan de manera presencial. Estos resultados contrastados con los datos cuantitativos permiten inferir que el poco conocimiento sobre mediación policial que le brinda la institución a los ciudadanos del corregimiento Palomino obedece a las condiciones necesarias de presencia en la zona para ejecutar las campañas de divulgación.

Respecto a las condiciones generales de la Guía para para fortalecer la implementación de la mediación policial en el sector rural de Colombia, se incluyen los datos relacionados con la respuesta a las preguntas número tres (03) y siguientes, hasta la pregunta número doce (12), donde se visibilizaron las siguientes categorías:

- $\quad$ Presentación y estilo de la Guía.

- $\quad$ Suficiencia y pertinencia del módulo 1.

- $\quad$ Suficiencia y pertinencia del módulo 2 .

- $\quad$ Suficiencia y pertinencia del módulo 3.

- $\quad$ Suficiencia y pertinencia del módulo 4 .

- Utilidad de la guía.

- Utilidad de los formatos incluidos en la guía.

En la categoría relacionada con la presentación y estilo de la Guía para para fortalecer la implementación de la mediación policial en el sector rural de Colombia, se evidencia que los resultados alcanzan una saturación en relación con la necesidad de modificar el estilo de la mencionada guía, para que se ajuste con la imagen corporativa de la Policía Nacional de Colombia, en ese sentido se debe tener en cuenta el reglamento de uso de identidad e imagen establecido mediante resolución número 06676 del 24 de diciembre de 2018 (Dirección General Policía Nacional de Colombia, 2018) que establece los parámetros para el uso de fotografías y escudos, colores y demás componentes de la imagen institucional, adicionalmente se deben acoger los lineamientos para el control de documentos en la Policía Nacional de Colombia establecido mediante la Guía DS-GU-0015 (Oficina de Planeación Policía Nacional de Colombia, 2018), que determina el procedimiento y los parámetros para la institucionalización de nuevos documentos estandarizados para la institución.

Al mismo tenor se hace necesario modificar la generalidad de los apartes de texto del documento donde se menciona la ley 1801 de 2016 para inscribir el nombre actual de la norma: "Código Nacional de Convivencia y Seguridad Ciudadana".

Los resultados sobre la valoración de la suficiencia y pertinencia de la información contenida en el módulo número uno de la guía objeto de estudio, permiten concretar las dos alternativas incluidas para diagnosticar las condiciones de los conflictos en la jurisdicción cumplen con el propósito y presentan condiciones sencillas para su ejecución, sin embargo, se visibilizó que no siempre es posible la ejecución de la primera alternativa que incluye los datos estadísticos de SIEDCO, Cámara de Comercio u otra institución que tenga injerencia en la localidad, tal como se visibilizó en el caso de la consecución de datos para el corregimiento de Palomino. Consecuentemente la aplicación práctica de la alternativa numero dos demostró ser práctica y concreta para su aplicación en campo, permitiendo conocer las condiciones de los conflictos desde la percepción de una muestra de ciudadanos residentes.

En la categoría de suficiencia y pertinencia del contenido textual del módulo número dos de la Guia en estudio, se evidenció una saturación 
de los resultados que sugiere la supresión del texto relacionado con los medios materiales de policía, lo cual también se identificó por los investigadores durante el proceso de ajustes preliminares a la Guía para su socialización. Esta inferencia también se sustenta en el hecho de que la mediación policial corresponde a un medió inmaterial de policía como los describe el artículo 149 del Código Nacional de Convivencia y Seguridad Ciudadana y que los medios materiales de policía no son parte de los objetivos de implementación trazados por la guía en evaluación.

Respecto a la categoría que concentra los resultados sobre la suficiencia y pertinencia del contenido en el módulo número tres de la Guía para para fortalecer la implementación de la mediación policial en el sector rural de Colombia, se identificó que la ruta de implementación es procedente para las dos jurisdicciones seleccionadas en este estudio, adicionalmente la totalidad de los sujetos entrevistados coincidieron en la suficiencia del contenido para la capacitación de los funcionarios de policía en temas de mediación policial, los cuales fueron ajustados por los investigadores en cuanto a su accesibilidad y presentación como acción previa registrada en el diario de campo.

La valoración de suficiencia y pertinencia para el módulo número cuatro de la guía muestra que existe una saturación en cuanto al desconocimiento que tiene la ciudadanía frente a la mediación policial como medio para la resolución de sus conflictos, lo cual fue corroborado por los mismos ciudadanos involucrados en la muestra tomada en el corregimiento Palomino quienes en su mayoría manifestaron que no han recibido información al respecto por parte de la Policía Nacional y por ende los ciudadanos no hacen uso de este medio inmaterial de policía para la resolución de sus conflictos.
La utilidad de la Guía para para fortalecer la implementación de la mediación policial en el sector rural de Colombia, fue valorada como un documento práctico, de fácil aplicación y que soporta el procedimiento de implementación de la mediación policial, considerándose útil para el ejercicio de la actividad de policía en el ámbito rural. En ese sentido los expertos entrevistados coincidieron en que su aplicación se debe gestar principalmente a los funcionarios de policía que laboran en el ámbito rural (carabineros), considerándose entonces la inferencia de que el eventual proceso de implementación se ejecute principalmente desde la Dirección de Carabineros y Seguridad Rural teniendo en cuenta que de acuerdo a la resolución No. 01583 de 2014 tiene dentro de sus funciones el desarrollo de la política de seguridad ciudadana, inherente a la prestación del servicio de policía en el ámbito rural, a través de planes, estrategias y programas de gerencia del servicio, prevención, disuasión y control de delitos y contravenciones (Dirección General Policía Nacional de Colombia, 2014).

Por último, se confirmó que los formatos establecidos en la guía son útiles y suficientes para la implementación de la mediación policial en el ámbito rural, particularmente en las dos localidades involucradas en el presente estudio.

\section{DISCUSIÓN}

En el desarrollo de las acciones de validación práctica de la Guía para fortalecer la implementación de la mediación policial en el sector rural de Colombia, se ejecutaron las acciones sistemáticas que permitieron comprobar el importante aporte que este documento proporciona a los uniformados que prestan su servicio en el ámbito rural, adicionalmente se identificaron las oportunidades y dificultades de cada uno de los cuatro módulos, lo cuales permitieron establecer los ajustes y complementos para la guía en estudio de la siguiente manera: 
Tabla 13, valoración de oportunidades o dificultades de la Guía objeto de estudio

\begin{tabular}{|c|c|c|}
\hline Criterio o Sección de la guía & $\begin{array}{l}\text { Oportunidades o dificultades identificadas en la } \\
\text { validación }\end{array}$ & Acciones tomadas \\
\hline $\begin{array}{l}\text { Estructura y estilo del } \\
\text { documento }\end{array}$ & $\begin{array}{l}\text { Oportunidad: la estructura general del documento } \\
\text { es comprensible y práctico. } \\
\text { Oportunidad: la guía fue valorada como un } \\
\text { instrumento útil para el fortalecimiento del proceso } \\
\text { de implementación de la mediación policial en } \\
\text { el ámbito rural y su institucionalización debe } \\
\text { impulsarse desde la Dirección de Carabineros y } \\
\text { Seguridad Rural. } \\
\text { Dificultad: el proceso de implementación a nivel } \\
\text { institucional exige el cumplimiento de los estándares } \\
\text { documentales y de imagen corporativa. }\end{array}$ & $\begin{array}{l}\text { Se ajustó el texto, las } \\
\text { imágenes, enlaces } \\
\text { y colores en la } \\
\text { generalidad de la } \\
\text { Guía para fortalecer } \\
\text { la implementación de } \\
\text { la mediación policial } \\
\text { en el sector rural de } \\
\text { Colombia. }\end{array}$ \\
\hline $\begin{array}{c}\text { Módulo 1: Identificación de } \\
\text { propiedades y características } \\
\text { del conflicto }\end{array}$ & $\begin{array}{l}\text { Oportunidad: las dos alternativas incluidas en } \\
\text { el módulo son pertinentes para establecer las } \\
\text { propiedades y características del conflicto en la } \\
\text { jurisdicción, distinguiéndose la alternativa dos, } \\
\text { por su condición práctica e independiente en la } \\
\text { aplicación por parte de los funcionarios de policía. } \\
\text { Dificultad: la aplicación de la alternativa uno, } \\
\text { depende de la disponibilidad de información } \\
\text { estadística para la jurisdicción }\end{array}$ & $\begin{array}{l}\text { Se ajustó y valido el } \\
\text { cuestionario incluido } \\
\text { como instrumento para } \\
\text { la alternativa } 2 \text {, con el } \\
\text { propósito de generalizar } \\
\text { su eventual aplicación a } \\
\text { cualquier jurisdicción del } \\
\text { ámbito rural. }\end{array}$ \\
\hline $\begin{array}{l}\text { Módulo 2: marco legal } \\
\text { y procedimientos en la } \\
\text { mediación policial }\end{array}$ & $\begin{array}{l}\text { Oportunidad: la información normativa sobre } \\
\text { mediación policial tiene fundamento jurídico valido } \\
\text { y reconocido por los funcionarios de policía. } \\
\text { Dificultad: Se identificó un marco normativo que no } \\
\text { hace parte de los medios inmateriales de policía, } \\
\text { que genera posibles confusiones frente al concepto } \\
\text { general de la aplicación de la mediación policial. }\end{array}$ & $\begin{array}{c}\text { Se suprime la } \\
\text { información normativa } \\
\text { relacionada con los } \\
\text { medios materiales de } \\
\text { policía. }\end{array}$ \\
\hline $\begin{array}{l}\text { Módulo 3: Ruta de } \\
\text { implementación, } \\
\text { capacitación y seguimiento. }\end{array}$ & $\begin{array}{l}\text { Oportunidad: la ruta de implementación establecida } \\
\text { en la guía se ajusta procedimentalmente a las } \\
\text { jurisdicciones involucradas en el estudio. } \\
\text { Oportunidad: el contenido relacionado con las } \\
\text { oportunidades de capacitación y seguimiento para } \\
\text { los funcionarios es suficiente. } \\
\text { Dificultad: los enlaces (URL) incluidos en el } \\
\text { documento no son funcionales. }\end{array}$ & $\begin{array}{l}\text { Se habilita el } \\
\text { funcionamiento de los } \\
\text { enlaces relacionados con } \\
\text { los cursos de formación. }\end{array}$ \\
\hline $\begin{array}{c}\text { Módulo 4: importancia de la } \\
\text { divulgación de la mediación } \\
\text { policial }\end{array}$ & $\begin{array}{l}\text { Oportunidad: se identificó un desconocimiento por } \\
\text { parte de los ciudadanos encuestados en cuanto al } \\
\text { conocimiento de la medicación policial como medio } \\
\text { para la resolución de conflictos, que precisa la } \\
\text { necesidad de implementación de la guía objeto de } \\
\text { estudio por parte de la Policía Nacional de Colombia. } \\
\text { Oportunidad: la necesidad de implementación } \\
\text { de la presente guía se incrementa, teniendo en } \\
\text { cuenta que la muestra involucrada en la encuesta } \\
\text { manifiesta su intensión de usar las oficinas de } \\
\text { mediación policial para dirimir sus conflictos. }\end{array}$ & No se generan acciones \\
\hline
\end{tabular}


En síntesis, se establecieron ocho oportunidades y cuatro dificultades durante el proceso de validación práctica de la Guía para fortalecer la implementación de la mediación policial en el sector rural de Colombia, implicando que las dificultades en general se relacionaban con el contenido del documento sin que esto afectara sustancialmente el proceso de implementación en cada una de las jurisdicciones seleccionadas en el estudio, adicionalmente estas dificultades permitieron identificar los aspectos por complementar en la guía para que se ajuste a lo requeridos en el marco de un eventual proceso de implementación que lidere la Dirección de Carabineros y Seguridad Rural.

En el marco de la validación práctica de la Guía para fortalecer la implementación de la mediación policial en el sector rural de Colombia, se ejecutó una prueba piloto en dos poblaciones pertenecientes al ámbito rural que permitió concretar las oportunidades y dificultades del proceso como parte de las acciones de retroalimentación para efectuar las mejoras al documento para proponerlo como una oportunidad de implementación en el marco del servicio de policía rural por parte de la Dirección de Carabineros y Seguridad Rural.

Durante la ejecución de la fase cuantitativa se confirmó una alta probabilidad de ocurrencia de conflictos que es común en las dos localidades donde se ejecutó el estudio lo cual confirma la importante necesidad de contar con una guía aplicable a cualquier comunidad catalogada como rural.

En la valoración de las causas que generan los conflictos resultó ser común en las dos localidades, atribuyéndole el fenómeno a los chismes y comentarios mal intencionados, lo cual sugiere que es una causa recurrente que debe analizarse para su intervención desde el punto de vista del comportamiento social.

Cuando se trata de conflictos relacionados con los miembros más antiguos de la comunidad, en los dos casos analizados se evidenció una menor probabilidad de ocurrencia que podría atribuirse al significado e importancia que la sociedad colombiana les imprime a las personas en edad adulta mayor.

El desarrollo de la fase cuantitativa del estudio que involucró ciudadanos residentes de cada localidad se demostró que la generalidad de ellos usaría la oficina de mediación policial para dirimir sus conflictos, permitiendo prever la eventual efectividad de esta estrategia para mejorar las condiciones de convivencia y seguridad en las áreas rurales.

La relación de los resultados en relación con el conocimiento de los ciudadanos frente a la mediación es directamente proporcional a la aceptación del mecanismo de mediación policial para la resolución de sus conflictos.

Los ajustes requeridos en la generalidad de los modulo contenido en la Guía para fortalecer la implementación de la mediación policial en el sector rural de Colombia, tienen que ver con circunstancias subsanables ante un eventual proceso de estandarización e implementación por parte de la Policía Nacional de Colombia.

\section{REFERENCIAS BIBLIOGRÁFICAS}

Becerril, D., \& Reche, P. A. (2016). Revista de Paz y Conflictos, 9(2), 103-123. Recuperado el 15 de mayo de 2020, de https://dialnet.unirioja.es/servlet/ articulo?codigo $=5891437$

Camacho, B. E., \& Céspedes, P. N. (2018). Habilidades socio-emocionales: un elemento esencial en el policía como mediador en Colombia. Revista Diversitas - Perspectivas en Psicología(ISSN: 1794-9998), 279-295. doi:https://doi.org/10.15332/s17949998.2018.0002.06 
Cámara de Comercio de Bogotá. (1 de diciembre de 2017). Centro de Información Empresarial (CIEB). Recuperado el 06 de junio de 2020, de Mediación policial en Colombia: Bases para su implementación: http://hdl.handle. net/11520/19663

Céspedes, P. N., \& Ramirez, S. G. (14 de mayo de 2016). Rol mediador de la Policía Nacionalde Colombia en el posconflicto: Un estudio del discurso de expertos con AEDIT. Revista Diversitas - perspectivas de Psicología, 12(2), 183-199. Recuperado el 30 de julio de 2020, de http://www.scielo.org.co/pdf/ dpp/v12n2/v12n2a03.pdf

Céspedes, P. N., Cervantes, E. L., Tafur, D. D., Pabón, M. L., Palomino, L. N., \& Fajardo, P. E. (27 de enero de 2020). Fortalecimiento de las habilidades psicosociales para mejorar el servicio de policía y aumentar la confianza social. Revista Boletin redipe(ISSN: 22561536), 88-112. Recuperado el 30 de julio de 2020, de https://revista.redipe.org/ index.php/1/article/download/977/890

Congreso de la Republica de Colombia . (31 de agosto de 2004). Ley 906 de 2004. Obtenido de Secretaría del senado : http://www.secretariasenado.gov.co/ senado/basedoc/ley_09060_204a.html

Congreso de la República de Colombia . (29 de julio de 2016). Código Nacional de Policía y Convivencia . Ley 1801. Bogotá D.C., Colombia: Congreso de Colombia .

Departamento Administrativo Nacional de Estadística. (1 de enero de 2018). Dane apra todos. Recuperado el 10 de julio de 2020, de Censo nacional de población y vivienda 2018 Colombia: https://www. dane.gov.co/index.php/estadisticas-portema/demografia-y-poblacion/censonacional-de-poblacion-y-vivenda-2018

Dirección General Policía Nacional de Colombia. (24 de abril de 2014). Resolución por la cual se define la estructura orgánica interna y se determinan las funciones de la Dirección de Carabineros y Seguridad Rural y se dictan unas disposiciones. Resolución No. 01583. Bogotá D. C., Colombia.: Dirección General Policía Nacional de Colombia. Recuperado el 10 de agosto de 2020, de file://C:/Users/Jhon/AppData/Local/ Temp/resolucion_06965_estructura_ organica_dicar.pdf

Dirección General Policía Nacional de Colombia. (24 de diciembre de 2018). Reglamento de uso de la identidad e imagen de la Policía Nacional de Colombia. Resolución 0676. Bogota D. C., Colombia: Policía Nacional de Colombia.

Google Inc. (1 de agosto de 2020). G Suite Essentials. Recuperado el 5 de agosto de 2020, de Google: https:// gsuite.google.com/intl/es-419/ essentials/?utm_source=google\&utm _ medium $=c p c \& u t m \_c a m p a i g n=l a t a m-$ CO-all-es-dr-bkws-all-all-trial-elatam-1009103-LUAC0010719GoogleMeet\&utm_content $=$ text a d - n o n e - n o n e - DE V _ c CRE_443002528778-ADGP_ Hybrid\%20\%7C\%20AW\%20SEM\%

Grupo de investigación ESGON. (2019). Guía para fortalecer la implementación de la mediación policial en el sector rural de Colombia. Espinal: Escuela de Policía Gabriel Gonzalez. Recuperado el 22 de febrero de 2020, de https://es.calameo. com/books/00610641934601d357759 
Hernández, S. R., Fernandez, C. C., \& Baptista, L. P. (2014). Metodología de la Investigación (Sexta ed.). México, México: McGraw Hill.

Hogg, M., \& Vaughan, G. (2010). Psocología Social (Vol. 5). Madrid: Médica panamericana S.A. Recuperado el 30 de junio de 2020, de https://books. google.com.co/books?id=7crhnqbQIR4 C\&pg $=$ PA577\&lpg $=$ PA577\& $d q=e d a d+e$ $\mathrm{n}+\mathrm{la}+$ que + mas + interact $\% \mathrm{C} 3 \% \mathrm{BAa}+\mathrm{so}$ cialmente+la+persona\&source=bl\&ots= 9H-IZqFvbX\&sig=ACfU3U2pnazSU5XP IBeeZewSLvE9n1tW2g\&hl=es\&sa=X \&ved=2ahUKEwiwmOqT1anqAhUwnAKHbN2DiAQ6AEwBXoECAcQA

Llauradó, O. (12 de enero de 2014). Netquest . Obtenido de La escala de Likert: qué es y cómo utilizarla: https://www.netquest. $\mathrm{com} / \mathrm{blog} / \mathrm{es} / \mathrm{la}$-escala-de-likert-que-esy-como-utilizarla

Oficina de Planeación Policía Nacional de Colombia. (21 de septiembre de 2018). Lineamientos para el control de documentos en la Policía Nacional . Guía 1DS-GU-0015. Bogotá D. C. , Colombia : Oficina de Planeación Policía Nacional de Colombia.

Policía Nacional de Colombia. (29 de diciembre de 2017). Manual de Ciencia, Tecnología e Innovación para la Policía Nacional de Colombia. Resolución No. 06706. Bogotá D.C., Colombia: Policía Nacional de Colombia.

Policía Nacional de Colombia. (14 de enero de 2020). Policía Nacional de Colombia. Recuperado el 14 de enero de 2020, de direccionamiento-tecnologico: https:// policia.gov.co/files/direccionamientotecnologicoxls

Policía Nacional de Colombia. (21 de mayo de
2020). Registro Nacional de Medidas Correctivas - RNMC. Recuperado el 21 de mayo de 2020, de srvcnpc.policia. gov.co/Cnpc/frm_cnp_reportes.aspx

Riley, M., Prenzler, T., \& McKillop, N. (2 de julio de 2018). Alternative dispute resolution and mediation of complaints against police in Australia and New Zealand, Police Practice and Research. Police Practice and Research, 21, 3-17. doi:https://doi. org/10.1080/15614263.2018.1500284

Steele Garza, J. G. (2018). Mediación policial. Un protocolo de prevención del delito y cultura de paz. Justicia, 23(34), 471489. Recuperado el 25 de julio de 2020

Suarez, C. M., Camacho, B. E., Céspedez, P. N., Rozo, E. M., \& Matiz, R. A. (2016). La mediación como herramienta de paz en el servicio de policía. Bogotá D.C.: Escuela de cadetes de policía General Francisco de Paula Santander. Obtenido de http://168.227.244.104:8080/ bitstream/handle/123456789/1079/ MEDIACIONHERRAMIENTAPAZ. pdf? sequence $=1$ \&isAllowed $=y$ 